\title{
Review on Factors Affecting the Nutritional Status of Women in Ethiopia
}

\author{
Yimer Mihretie* \\ Department of Food Science and Nutrition, Jigjiga University, Ethiopia \\ *Corresponding author: Yimer Mihretie, Department of Food Science and Nutrition, Jigiga University, College of Dry land Agriculture, Ethiopia
}

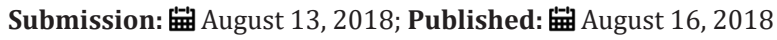

\begin{abstract}
Adequate nutritional status of women is important for good health and increased work capacity of women as well as for the health of their children. However under nutrition and poor health adversely affect the well-being of millions of people in the developing world. More than 3.5 million women and children less than five aged in developing countries died each year due to the underlying cause of under nutrition. The purpose of this article is to review the factors affecting the nutritional status of women in Ethiopia. Women are mostly venerable to malnutrion because of the intake of unbalanced foods due to low economic status, low education background, marital status and age. Women of the reproductive age are amongst the most vulnerable to malnutrition. Additionally place of women residence was one factor contributing to the nutritional variation between rural and urban women. There has been a variation between married and unmarried women in their nutritional status. The unmarried and divorced women had relatively high malnutrition problem than married one. However, this argument in the economic status of women is different. Whether the women have got married or unmarried, the economic status could be the cause of malnutrition if they are coming from low economic family. Therefore in order to have the women better understanding about nutritional status, they should be encouraged to attend nutrition education.
\end{abstract}

Keywords: Education; Malnutrition; Marital status; Nutritional status; Under nutrition; Women

\section{Introduction}

Adequate nutritional status of women is important for good health and increased work capacity of women as well as for the health of their children. Under nutrition and poor health from preventable causes disproportionately affect the well-being of millions of people in the developing world. Factors at individual, household and community level or a combination may contribute to poor nutrition and health status of women. In particular malnutrition among women is likely to have a major impact on their health as well as their children's health. More than 3.5 million women and children under five aged in developing countries died each year due to the underlying cause of under nutrition.

Women are more likely to suffer from nutritional deficiency than men for several reasons including their reproductive biology, low social status, poverty and lack of education. In addition, sociocultural traditions and disparities in household work patterns could increase women's chance of being malnourished. In this regard, with a range of 5 to 20 percent of women in various African countries are underweight. Women in low-income settings often consume inadequate amount of micronutrients because of resource limitation. This leads too many African women to have low weight for- height as measured by a body mass index of less than 18.5. They have a limited intake of animal source foods, fruits and vegetables. Additionally the intake of micronutrients less than the recommended values increase women's risk of micronutrient deficiencies.

Severely malnourished mothers have reduced lactation performance contributing to the increased risk of child mortality. Nutritional requirements during lactation are greater than during pregnancy. If a mother is well nourished during pregnancy, she will have adequate fat and other nutrient reserves that can be used to compensate partially for her additional requirements. Mothers should be counselled about the need for an adequate diet in order to achieve optimal lactation and sustain it without depleting their nutrient stores. Particular attention should be given to intakes of protein, calcium and vitamins. Lactating mothers from low-income settings are considered as nutritionally vulnerable group. Due to the nursing process mothers are subjected to nutritional stresses. Frequent pregnancies followed by lactation increase the health risk of mothers resulting in a high maternal mortality.

A nursing mother produces 0.7 to 0.8 litters of milk per day, containing 330 milligrams of calcium per liter. This requires an extra energy expenditure of at least 500 Calories per day. The quality 
of breast milk is only affected in extreme cases of deprivation, or by excessive intake of a particular food. This literature is aiming to review the factors affecting the nutritional status of women in Ethiopia.

\section{Women's Nutrition}

Some evidence in developing countries indicated that malnourished individuals, that is, women with a body mass index (BMI) below 18.5 showed a progressive increase in mortality rates as well as increased risk of illness [1]. For social and biological reasons, women of the reproductive age are amongst the most vulnerable to malnutrition. Increased perinatal andneonatal mortality, a higher risk of low birth weight babies, stillbirths, and miscarriage are some of the consequences of malnutrition in women [2]. Some of the socioeconomic and demographic factors explaining women's nutrition according to studies donein different places are reviewed below.

\section{Household economic status}

The economic status of a household is an indicator of access to adequate food supplies, use of health services, availability of improved water sources, and sanitation facilities that are prime determinants of child and maternal nutritional status [3]. A study of most of the DHS Demographic Health Surveys conducted in developing countries [4] and a study in the Southern Nations, Nationalities and Peoples Region (SNNPR) of Ethiopia [5] showed that women from low economic status households were affected consistently by malnutrition.

\section{Education status of women}

Education is one of the most important resources that enable women to provide appropriate care for their children, which is an important determinant of children's growth and development [6] Women who even received a minimal education have generally more awareness than those who had no education of how to utilize available resources for the improvement of their own nutritional status and that of their families. Education may enable the women to make independent decisions, to be accepted by other household members, and to have greater access to household resources that are important to improve their nutritional status [7]. A comparative study on maternal malnutrition in ten sub-Saharan African countries [4] and a study in the SNNPR of Ethiopia [5] showed that the higher the level of education the lower the percentage of undernourished women. Similarly, studies in the Philippines [8-12], have shown a decreased incidence of malnutrition among young children with an increase in the level of mothers' education.

\section{Place of residence}

According to a comparative study on maternal nutritional status, 16 out of the 18 DHS conducted in African countries [5] and a study in the SNNPR of Ethiopia [5] showed that rural women are more likely to suffer from chronic energy deficiency than women living in urban areas. These higher rates of rural malnutrition were also reported by local studies in Ethiopia [9]. Similarly the studies on child nutrition $[11,12]$ have shown comparatively higher levels of stunting among rural children than those of urban.

\section{Age of women}

Women's age and parity are important factors that affect maternal depletion especially in high fertility countries [9]. DHS surveys conducted in Burkina Faso, Ghana, Malawi, Namibia, Niger, Senegal, and Zambia shown a greater proportion of mothers age 15-19 and 40-49 that exhibit chronic energy deficiencies (CED). A local study in Ethiopia has also shown that women in the youngest age group (15-19) and women in the old e stage group (45-49) are affected mostly by under nutrition [5].

\section{Marital status of women}

Marital status of the women is associated with household headship and other social a deconomic status of the women that affects their nutritional status. Nutritional and social security's could be endangered by a negative change in marital status. A study on the SNNPR Region of Ethiopia showed that women's malnutrition is significantly associated with marital status that indicates as compared to married women malnutrition is higher in unmarried rural and divorced/separated urban women [5].

\section{Conclusion}

Malnutrition among women is likely to have a major impact on their own health as well as their children's health. More than 3.5 million women and children under five aged in developing countries died each year due to the underlying cause of under nutrition. Women are more likely to suffer from nutritional deficiency than men for several reasons, including their reproductive biology, low social status, poverty and lack of education. Therefore, adequate nutritional status of women is important for good health and increased work capacity of women themselves as well as for the health of their children. Women of the reproductive age are amongst the most vulnerable to malnutrition and also Women who receive even a minimal education have generally better awareness than those who have no education of how to utilize available resources for the improvement of their own nutritional status and that of their families. All women should be encouraged to take nutrition education in order to keep their nutritional status in a well manner way, as well as to feed their children effectively.

\section{References}

1. Rotimi C, Okosun L, Johnson E, Owoaje T, Lawoyin M, et al. (1999) The distribution and mortality impact of chronic energy deficiency among adult Nigerian men and women. Eur J Clin Nutr 53(9): 734-739.

2. United Nations Children's Fund (UNICEF) (1993) Children \& women in Ethiopia, a situation report. Addis Ababa, Ethiopia.

3. United Nations Children's Fund (UNICEF) (1990) Strategies of improving nutrition of children and women in developing countries. New York, USA.

4. Samson T, Lakech G (2000) Malnutrition and enteric parasites among fewer than five children in Aynalem village, Tigray. Ethiopian Journal of Health Development 14(1): 67-75.

5. Teller H, Yimar G (2000) Levels and determinants of malnutrition in adolescent and adult women in southern Ethiopia. Ethiopian Journal of Health Development 14(1): 57-66. 
6. Shetty PS, James WP (1994) Body mass index: a measure of chronic energy deficiency in adults. FAO Food Nutr Pap 56: 1-57.

7. Von BJ, Kennedy E (1986) Commercialization of subsistence agriculture: income and nutritional effects in developing countries. Working Papers on Commercialization of Agriculture and Nutrition No 1, International Food Policy Research Institute. Washington, USA.

8. World Bank (1994) A new agenda for women's health and nutrition Washington, USA.

9. Zerihun T, Larson CP, Hanley JA (1997) Anthropometric status of oromo women of child bearing age in rural south-western Ethiopia. Ethiopian Journal of Health Development 11(3).
10. Statistics Department [Uganda], and Macro International Inc (1996) Uganda Demographic and Health Survey 1995. Calverton, Maryland, USA.

11. Sommerfelt AE, Kathryn S (1994) Children's nutritional status. DHS Comparative Studies No 12, Calverton, Maryland, USA.

12. Yimer G (2000) Malnutrition among children in southern Ethiopia: Levels and risk factors. Ethiopian Journal of Health Development 14(3): 283-292.
Creative Commons Attribution 4.0

International License

For possible submissions Click Here

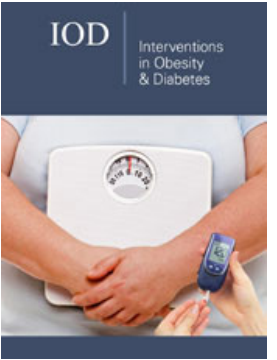

\section{Intervention in Obesity \& Diabetes}

\section{Benefits of Publishing with us}

- High-level peer review and editorial services

- Freely accessible online immediately upon publication

- Authors retain the copyright to their work

- Licensing it under a Creative Commons license

- Visibility through different online platforms 